\title{
Tratamento cirúrgico de união retardada e não-união de fraturas em cães: revisão de literatura
}

\section{Surgical treatment of delayed union and nonunion fractures in dogs: literature review}

\section{Tratamiento quirúrgico de unión retardada y no-unión de fracturas en perros: revisión de la literatura}

\begin{abstract}
Alexandre Schmaedecke1; Marília Lorenzoni Aceto²; Genílson Fernandes de Queiróz ${ }^{3}$; Angélica Cecília Tatarunas ${ }^{4}$; Maria Beatriz Cathony Zerwes ${ }^{5}$; Sandra Mastrocinque ${ }^{6}$; Cássio Ricardo Auada Ferrigno ${ }^{7}$
\end{abstract}

Departamento de Cirurgia da Faculdade de Medicina Veterinária e Zootecnia da Universidade de São Paulo - FMVZ/USP. São Paulo, SP, Brasil

\section{Resumo}

Objetivo: Analisar as diferentes formas de tratamento propostas para união retardada e não-união de fraturas em cães, levando em consideração a classificação do processo, condições encontradas e a viabilidade de cada tratamento. Fontes Pesquisadas: Foram pesquisadas as bases de dados LILACS, DEDALUS, PUBMED e o acervo da Biblioteca da Faculdade de Medicina Veterinária e Zootecnia da Universidade de São Paulo, no período de junho de 2003 a março de 2004. Síntese dos Dados: União retardada e não-união são eventos patológicos no processo de recuperação de fraturas, decorrentes de vários fatores físicos ou biológicos que resultam em uma inadequada reparação óssea. Dentre as causas, sem dúvida, a mais comum é a escolha inadequada do tratamento, gerando instabilidade, perda do aporte vascular e quebra da sequiência dos processos biológicos de cicatrização. Conclusões: Estudos experimentais e clínicos indicam uma variedade muito grande de tratamentos, destacando-se entre eles o uso de proteínas osteoindutoras.

Palavras-chave: Pseudo-artrose. Consolidação da fratura. Fixação da fratura. Calo ósseo. Transplante ósseo. Osteogênese. Substâncias de crescimento. Proteínas morfogenéticas ósseas. Cães. 


\section{Introdução}

A meta a ser alcançada em cirurgia ortopédica é a completa reparação óssea, com recuperação da função do membro envolvido. No entanto, complicações podem ser observadas neste processo, inviabilizando a completa recuperação do tecido ósseo e resultando na conseqüente perda da função do membro ${ }^{1}$.

O processo de cicatrização óssea respeita uma série de eventos biológicos ordenados, conseqüientes à fratura, que passam por estágios de formação de tecido de granulação, formação de calo ósseo e remodelação ${ }^{2}$. Deste modo, na maioria das fraturas, mesmo não sendo tratadas, haverá um processo de reparação óssea, ainda que tal processo esteja associado à perda de função do membro afetado ${ }^{3}$.

A violação dos princípios da cirurgia ortopédica é uma das mais importantes causas na falha da recuperação de fraturas, uma vez que as corretas aplicação e escolha das técnicas ortopédicas e a interação entre cirurgião e proprietário do animal são requisitos fundamentais para o sucesso do tratamento $^{1,3}$. A falha de processos biológicos do paciente e infecções são fatores que também influenciam nas etapas de reparação. A ocorrência de um ou mais fatores acarretam os processos de união retardada ou não-união óssea ${ }^{1,3,4}$.

O tratamento de não-uniões, uniões retardadas e outros problemas de perda óssea requerem a restauração do alinhamento, fixação estável e, em alguns casos, o uso de enxertos ou substitutos ósseos ${ }^{5,6}$. O desenvolvimento da biotecnologia tem oferecido novas ferramentas de tratamento das patologias ósseas, estimulando e acelerando o processo de reparação ${ }^{7}$.

O objetivo da presente revisão foi analisar as diferentes formas de tratamento propostas para união retardada e não-união de fraturas em cães, levando em consideração a classificação do processo, condições encontradas e a viabilidade de cada tratamento.

\section{Definição}

Muitas são as causas apontadas para os quadros de união retardada e não-união de fraturas, tais como imobilização inadequada da fratura, intervalo muito grande entre as margens do foco de fratura, perda de suprimento sangüíneo, infecção, hiperemia, compressão, quantidade excessiva de implantes, cominução severa, uso de implantes feitos com material não-apropriado, manejo pós-operatório impróprio e fatores metabóli$\cos ^{1}$.

União retardada é definida como uma fratura que não apresentou completa reparação no tempo normalmente requerido pela posição e tipo da fratura. Já no processo de não-união, a reparação parou, não apresentando progresso em seqüência de radiografias. A fratura não irá consolidar sem intervenção cirúrgica. No entanto, na ortopedia humana, uma fratura não pode ser classificada como não-união até, no mínimo, 6 meses após a lesão ${ }^{8}$. O termo pseudoartrose, embora seja clínica e histologicamente diferente dos processos de não-união fibrosos mais comuns, é considerado como sinônimo desses últimos ${ }^{3}$.

A classificação dos quadros de não-união, baseada segundo padrões de suprimento sangüíneo e potencial osteogênico ${ }^{9}$, é dividida em dois grupos distintos: viáveis e não-viáveis.

Não-uniões viáveis são fraturas biologicamente ativas, caracterizadas por grau variável de reação óssea proliferativa, com interposição de tecido cartilaginoso e fibroso, apresentando três variações conforme a disposição desses tecidos: hipervascular ou em pata-deelefante é resultante de quadros nos quais não houve uma correta redução das forças rotacionais; moderadamente hipervascular ou em casco-de-cavalo não apresenta um calo ósseo abundante, como a anterior, e é observada principalmente em fixações instáveis com uso de placas e parafusos; oligotrófica, que, apesar de ser considerada como reativa, apresenta pouca ou nenhuma formação de calo ósseo. Já os processos de não- 
viáveis, de acordo com Weber e $\mathrm{Cech}^{9}$ podem ser divididos em: distrófica, cominutiva, por defeitos ou atrófica. A característica desses processos é a ausência da formação de calo ósseo, com presença de terminações necróticas ou osteoporóticas e perda da atividade osteogênica ${ }^{1,3}$.

\section{Diagnóstico}

É difícil definir o tempo exato para se identificar um processo de união retardada e/ou não-união de fraturas, uma vez que muitos fatores podem influenciar no período de reparação. Idade do paciente, estado nutricional, configuração e local da fratura, presença de doenças metabólicas concomitantes, infecção, administração de drogas e grau de acometimento de tecidos moles adjacentes ${ }^{3}$ exemplificam um pouco desses fatores. Fatores físicos, como a presença de intervalos muito grandes entre as extremidades da fratura e o uso de método de fixação inadequada impedem a anastomose da vascularização intramedular, vascularização do calo mole e formação do calo ósseo além do trabalho de união realizado pelo tecido fibroso adjacente ${ }^{4}$.

O diagnóstico destes quadros geralmente é tomado mediante avaliação clínica e radiográfica, feitas em período de semanas após a efetivação do diagnóstico final. O procedimento radiográfico, além de identificar o processo, é fundamental para a decisão do tratamento a ser instituído'.

No intuito de diminuir o tempo de diagnóstico de quadros de não-união, estudo foi desenvolvidopara a mensuração de parâmetros bioquímicos que identificassem precocemente quadros de não-união, e analisassem a possibilidade de quadros infecciosos durante $o$ pós-operatório. Os padrões de concentrações séricas de marcadores do metabolismo ósseo - osteocalcina (OC), fosfatase alcalina ósteo-específica (BS-ALP), e desoxipiridinolina (DPYR), analisados em conjunto, podem apresentar um perfil confiável da atividade osteogênica, além de proverem com $96 \%$ de acurácia a predição de um estado de osteomielite com 4 semanas de pós-operatório ${ }^{10}$.
Estudo radiográfico utilizando a técnica de absortiometria óssea ${ }^{11}$ apresentou resultados significativos em comparação à técnica radiográfica convencional. A técnica proposta definiu quadros de não-união, em média, 8 semanas após a intervenção, e os primeiros resultados puderam ser obtidos em apenas $2,6 \mathrm{se}$ manas de pós-operatório, contra 4,6 semanas usadas pelas técnicas convencionais.

\section{Tratamento}

A meta primária em um tratamento de processos de não-união de fraturas é a promoção do retorno da atividade funcional do membro afetado. Para isso, devese identificar a causa primária do desencadeamento do processo e eliminá-la ${ }^{8}$, determinando se a normalidade está no ambiente biológico ou mecânico, ou em ambos $^{6}$. Estabilizar a fratura, promover uma revascularização e estimulação de formação óssea são os eventos necessários para a ativação da união. Devem ser removidos os elementos que não estão contribuindo para a fixação, como pinos intramedulares, placas, parafusos e fios de cerclagem soltos, quebrados ou inoperantes. Também é necessário reavivar os tecidos envolvidos e eliminar os focos de infecção ${ }^{3}$.

Na maioria dos casos de não-união e união retardada de fraturas, a restauração do alinhamento ósseo e uma fixação estável do osso são os únicos eventos para se alcançar uma reconstrução satisfatória. Entretanto, em muitos casos, medidas complementares como enxerto ósseo são necessárias para a estimulação do reparo ósseo e o preenchimento de defeitos, sendo este o principal protocolo no tratamento de não-uniões ${ }^{5,6,12}$. Nestes termos, pode-se afirmar que os enxertos ou substitutos ósseos utilizados tenham propriedades osteogênicas, osteocondutivas e osteoindutivas ${ }^{6}$. Estas características traduzem-se em fonte de células-tronco mesenquimais pluripotentes capazes de diferenciar-se em osteoblastos; em fatores de crescimento e diferenciações que orientem estas células a migrarem para o foco do defeito ósseo, proliferarem e se diferenciarem em osteoblastos; em uma matriz biodegradável ou estrutura para adesão e migração das 
células no defeito ósseo; em angiogênese e formação de rede vascular por meio da nova formação óssea.

Os auto-enxertos ósseos (Figura 1), embora amplamente utilizados para o tratamento de não-união, apresentam algumas desvantagens como o prolongamento do tempo cirúrgico e a morbidade do sítio doador $^{12}$. A quantidade de enxerto ósseo autólogo que pode ser obtida é limitada. Os aloenxertos ósseos apresentam diferentes propriedades biológicas ė apresentações, como matriz óssea desmineralizada, fragmentos de osso esponjoso, enxerto corticoesponjoso e cortical, além de segmentos osteocondrais e de ossos inteiros. Entre estes, a matriz óssea desmineralizada associada à medula óssea autógena, pode ser considerada uma alternativa para o tratamento das não-uniões quando não houver disponibilidade de enxerto autólogo esponjoso ou corticoesponjoso ${ }^{6}$.

A hidroxiapatita (Figura 2) associada à medula óssea autógena, pode ser utilizada como substituto ósseo e, associada à proteína osteogênica humana 1 (rhOP-1), no tratamento de defeitos e não-união óssea em ovelhas, obtendo reparo ósseo comparável ao uso de enxerto autólogo ${ }^{12}$. Quarto et al. ${ }^{13}$, Bruder et al. ${ }^{14} \mathrm{e}$ Kon et al. ${ }^{15}$, utilizaram células osteoprogenitoras autógenas de medula óssea expandidas in vitro e associadas a substitutos ósseos de cerâmica, obtendo reparo satisfatório dos defeitos ósseos.

Uma variedade de fatores de crescimento tem demonstrado expressão durante fases diferentes da reparação óssea experimental. Baseando-se nestes achados, houve grande interesse no desenvolvimento de aplicações clínicas com fatores de crescimento para o tratamento de não-uniões ósseas. Entre estes fatores estão o fator de transformação de crescimentobeta (TGF-[beta]), proteína morfogênica óssea (BPM), fator de crescimento de fibroblasto (FGF), fator de crescimento derivado de plaquetas (PDGF) (Figura 3), e hormônio do crescimento e fator de crescimento de insulina (IGF). As BPMs parecem ter um potencial osteogênico maior quando comparada aos outros fatores de crescimento ${ }^{16}$.

Estudos experimentais realizados em tratamento de quadros de não-união de fraturas de fêmur ${ }^{17,18}$, rá-

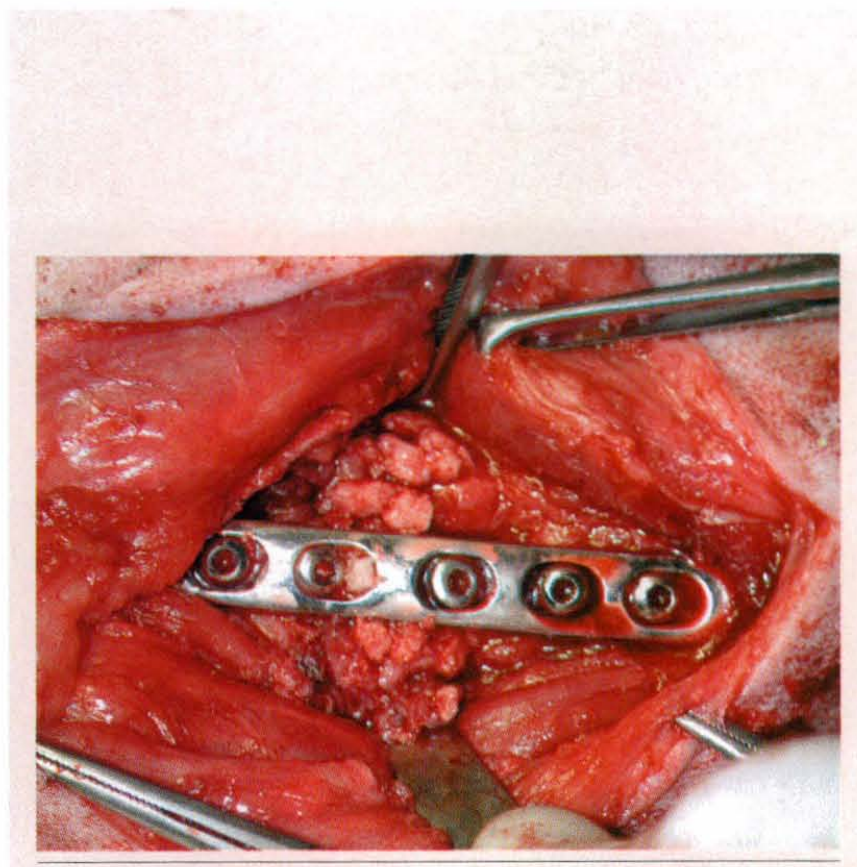

Figura 1 - Imagem fotográfica de fixação de não-união óssea de fêmur de cão com placa e parafusos de aço, com adição de enxerto autólogo de asa de ílio no sítio da nãounião (setas)

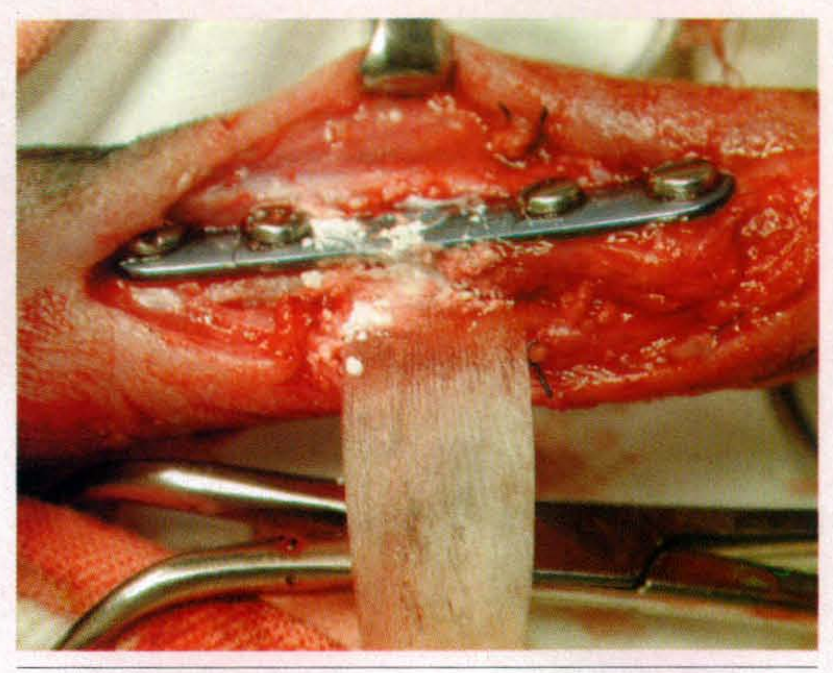

Figura 2 - Imagem fotográfica de fixação de não-união óssea em terço distal de rádio e ulna de cão com placa e parafusos de titânio, com adição de enxerto sintético de hidroxiapatita no sítio da não-união (seta) 


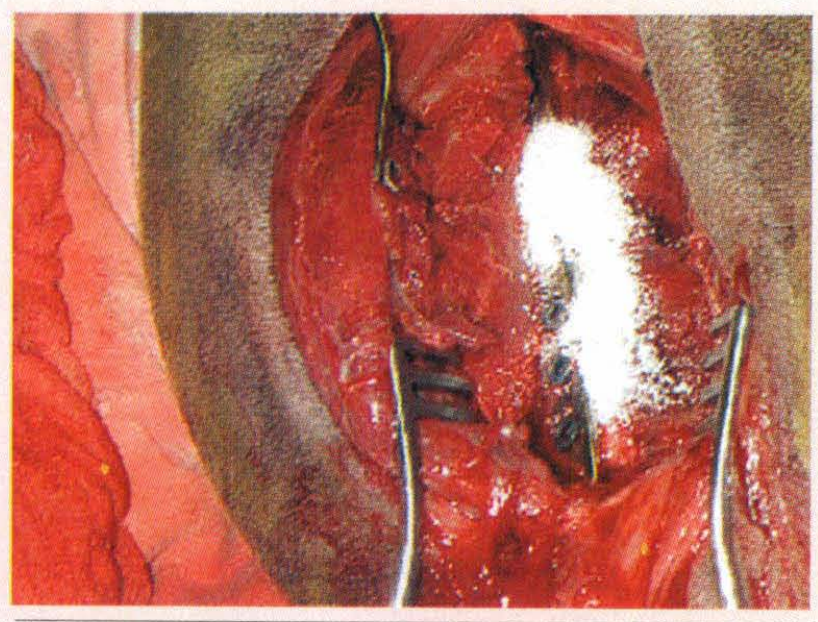

Figura 3 - Imagem fotográfica mostrando aspecto gelatinoso do plasma rico em plaquetas produzido a partir de sangue de cão, antes da implantação no foco de fratura

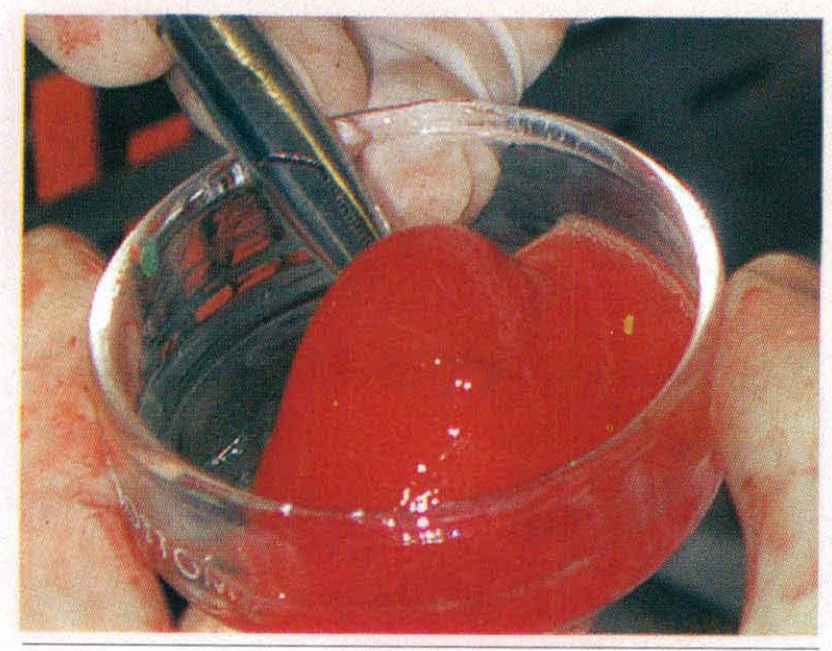

Figura 4 - Imagem fotográfica de fixação de não-união óssea em diáfise de fêmur de cão com placa e parafusos de aço, com acréscimo de enxerto sintético de osso liofilizado bovino adicionado de proteína morfogenética óssea (BMP) no sítio da não-união dio e ulna ${ }^{19}$ e tíbia ${ }^{20}$, com a utilização de BMP (Figura 4), apresentaram resultados significativamente melhores do que a simples utilização de técnicas adequadas de fixação.

Em estudo clínico humano envolvendo 122 pacientes com não união-óssea, foi comparado o uso de BPM-7 e auto-enxerto ósseo. Não houve diferença significativa nos resultados obtidos entre os tratamentos. Dessa forma, o uso de BPM-7 pode ser indicado diante da impossibilidade da obtenção de enxerto; é relevante lembrar que o procedimento de coleta pode levar a um quadro mórbido do sítio doador ${ }^{15}$. Além da possibilidade do uso de enxertos ósseos esponjosos, aliada às técnicas convencionais ${ }^{21}$, o uso dos indutores de crescimento ósseo constituem uma realidade no tratamento clínico desses processos ${ }^{17}$, observando que a BPM-2 e BPM-7 já são aprovadas pela The Food and Drug Administration ${ }^{7,16}$.

Embora o estudo da engenharia de tecidos tenha crescido na última década e o potencial de aplicação se tornado mais difundido, o conceito básico de que o reparo e a regeneração de tecidos biológicos pode ser guiado pela aplicação e pelo controle de células, materiais, e proteínas quimio-ativas, permanece central $^{22}$. Paralelamente, é possível à bioterapia poder tomar a forma de proteínas, genes ou células que podem ser usadas no tratamento de lesões ${ }^{7}$.

Yang $^{23}$, e Ikeda ${ }^{24}$ demonstraram por meio de estudos experimentais que a utilização de ultra-som de baixa intensidade promove a osteogênese, indicando-o para o tratamento de não-união de fraturas. Entretanto, em revisão de 52 trabalhos utilizando terapia com ondas de choque extracorporal (TOCE), Birnbaum et al. ${ }^{5}$, concluíram que os efeitos positivos da TOCE no tratamento das não-uniões permanecem obscuros, e são necessários estudos multicêntricos para definir suas indicações e especificações. A padronização das doses (taxas de energia e pulso) de tratamento é indispensável antes de classificar a TOCE como medicina baseada em evidência.

Outros estudos indicam a utilização de fixadores dinâmicos de Ilizarov para os tratamentos de não-união de fraturas de rádio e ulna e tíbia ${ }^{25,26}$. 


\section{Discussão}

A instituição de um processo de união retardada e/ou não-união de fraturas se dá por uma série de fatores mecânicos e biológicos, que, caso não diagnosticados nem corrigidos em tempo, culminam com a não recuperação do quadro, com conseqüente perda da função do membro afetado.

Dentre os fatores desencadeantes do processo, a falha na estabilização da fraturaé mais freqüente, quando comparada a outros fatores. Assim, o não-cumprimento das diretrizes básicas da cirurgia ortopédica parece ser a causa principal na taxa de insucesso do reparo ósseo. Desta forma, a utilização de técnicas adequadas e a experiência do cirurgião influem no sucesso das cirurgias ortopédicas.

Embora cada caso apresente um tratamento específico, muitas vezes só definido no transoperatório, Hulse ${ }^{27}$ descreve um método de padronização de escotha de implantes utilizando-se de escores, que levam em conta desde o tipo de fratura apresentada até as perspectivas de pós-operatório, tanto em relação ao paciente quanto ao proprietário. Desta forma, tenta definir, segundo cada escore, um tipo adequado de fixação, a fim de prevenir falhas durante a recuperação óssea.

Outro ponto a ser levantado em relação às intervenções ortopédicas é o chamado "mecanismo biológico de reparação de fraturas". Quanto menor for a manipulação do sítio de fratura, melhor se dará o processo de reparação. Quando se recebe um paciente, no sítio de fratura já se criou um microambiente propício para a reparação, quer seja em termos de vascularização, quer seja por formação de malha de fibrina que irá nortear o processo de regeneração óssea. Quando se expõe este sítio e ele é manipulado, muito ou quase todo esse processo é perdido, implicando um tempo maior de recuperação. Portanto, a escolha de uma técnica que anule ou diminua todas as forças que atuam sobre a fratura, aliada à mínima exposição e manipulação do foco aumenta significativamente a taxa de sucesso do tratamento, inclusive diminuindo o tempo de recuperação.
Casos específicos como cães de pequeno porte que apresentam fraturas em terço distal de rádio e ulna devem ser tratados com extremo cuidado e atenção, pois a vascularização local é extremamente pobre quando comparada a cães de raças mais pesadas ${ }^{28}$. Com a diminuição do aporte vascular, mais demorada e complicada se torna a recuperação óssea e, utilizando uma técnica inadequada de estabilização, as chances de se desenvolver um quadro de não-união são efetivamente maiores.

Outro caso muito especial é aquele em que são tratados pacientes exóticos. Pollock ${ }^{29}$ indica que esses pacientes necessitam manejo pós-operatório cuidadoso, tanto imediato quanto no período de hospitalização. Muitos desses animais necessitam de um lugar quieto, sem estresse e adequado às suas condições, em termos de acomodação, temperatura e segurança visual. Como tratam-se de animais geralmente inquietos, a recuperação pós-anestésica se dá em meio a tentativas constantes de movimentação. Desse modo, o estresse promovido pela movimentação sobre o implante ortopédicoé intenso logo após a cirurgia. A escolha do implante deve levar em consideração estes fatores, como forma de evitar complicações posteriores.

Quando são analisados os tratamentos propostos para os quadros de não-união, observa-se que pesquisas avançadas estão sendo desenvolvidas em termos de biologia molecular, surgindo os chamados promotores de crescimento ósseo, que já demonstraram alta capacidade de indução óssea. O auto-enxerto ósseo permanece como terapia tradicional e eficaz das não-uniões, juntamente com a adequada manutenção mecânica da estrutura óssea, porém apresenta algumas desvantagens. Diante da impossibilidade da obtenção do enxerto autógeno, ou na busca por novas formas de tratamento, a bioterapêutica e a engenharia tecidual vêm se desenvolvendo. Elas tomam forma por meio do uso de proteínas osteogênicas, genes, células, e materiais substitutos ósseos e de liberação de substâncias. As terapias baseadas em células e genes estão em estágio mais avançado quando comparadas ao uso de proteínas osteoindutoras, as quais têm seu uso clínico limitado pelas agências reguladoras governamentais norte-americanas ${ }^{7}$.

Os BMPs constituem técnica segura e eficaz para o tratamento destes quadros, sempre é claro, aliados à 
colocação de implantes corretos em relação à fixação e técnica. Embora estes fatores demonstrem grande potencial na otimização do reparo ósseo, o desenvolvimento de sistemas de liberação apropriados e o conhecimento da atividade biológica dos fatores no ambiente tecidual do hospedeiro, possibilitarão iniciar estratégias de engenharia tecidual e desenvolver técnicas cirúrgicas minimamente invasivas, reduzindo tanto a morbidade quanto o custo $^{16}$.

Embora os resultados da utilização de ondas de choque extracorporal ainda sejam conflitantes, e não tenha sido estabelecido um protocolo terapêutico apropriado, o estudo desse método de tratamento para as não-uniões ósseas justifica-se devido à taxa de complicação observada no tratamento cirúrgico de tal patologia $^{5}$. Ou seja, o TOCE apresenta como vantagem ser uma técnica não-invasiva e com baixas taxas de complicações, sendo necessário, entretanto, estudos futuros para determinar os níveis adequados de energia e impulsos nas diferentes indicações clínicas.

\section{Conclusões}

Em relação aos processos de não-união e união retardada de fraturas, vários são os tratamentos propostos; no entanto, o uso da biotecnologia no desenvolvimento de novos materiais tem sido efetivamente importante neste processo. O uso das proteínas morfogenéticas ósseas (BMP'S) e do plasma rico em plaquetas (PRP'S) têm demonstrado alta eficácia na resolução desta moléstia, com tempo menor de recuperação, bem como menor taxa de complicações comparados aos tratamentos convencionais.

Independentemente do aparecimento de novos materiais e técnicas, fica evidente que o fator mais importante no tratamento destas alterações é o respeito aos eventos biológicos intrínsecos ao processo de reparação de fraturas, por intermédio da escolha e da aplicação corretas da técnica mais indicada para cada fratura, situação na qual a experiência do cirurgião é fundamental.

\section{Abstract}

Objective: To analyze different proposed treatments for delayed union and nonunion fractures in dogs, taking into consideration process classification, encountered conditions and feasibility of each treatment. Data Sources: LILACS, DEDALUS, PUBMED databases and the bibliographic collection of the Library of the "Faculdade de Medicina Veterinária e Zootecnia da Universidade de São Paulo" (College of Veterinary Medicine and Zootechny from the University of São Paulo), São Paulo, SP, Brazil, were surveyed during the period comprised from June 2003 to March 2004. Data Synthesis: Retarded union and nonunion are pathological events in fractures repair process, arising out of several physical or biological factors that result in an inadequate bone repair. Amongst the causes, no question that the most common is the inadequate choice of treatment, generating instability, loss of vascular provision and breach of the sequence of the healing biological processes. Conclusions: Experimental and clinical studies indicate a large variety of treatments, standing out among them the use of osteoinducting proteins.

Keywords: Pseudoarthrosis. Fracture healing. Fracture fixation. Bony callus. Bone transplantation. Osteogenesis. Growth substances. Bone morphogenetic proteins. Dogs. 


\section{Resumen}

Objetivo: Analizar las diferentes formas de tratamiento propuestas, para unión retardada y no-unión de fracturas en canes, considerando la clasificación del proceso, condiciones encontradas y la viabilidad de cada tratamiento. Fuentes Pesquisadas: Se investigó en las bases de datos LILACS, DEDALUS, PUBMED y el acervo de la Biblioteca de la Facultad de Medicina Veterinaria y Zootecnia de la Universidad de São Paulo,Brasil, en el periodo de junio de 2003 a marzo de 2004. Síntesis de los Datos: Unión retardada y nounión son eventos patológicos en el proceso de recuperación de fracturas, originarias de varios factores físicos o biológicos que resultan en una inadecuada reparación ósea. Entre sus causas, la más común es sin duda la elección inadecuada del tratamiento originando inestabilidad, pérdida del aporte vascular y quiebra de la secuencia de los procesos biológicos de cicatrización. Conclusiones: Estudios experimentales y clínicos indican una variedad muy grande de tratamientos, con destaque entre ellos el uso de proteínas osteoinductoras.

Palabras-clave: Seudoartrosis. Curación de fractura. Fijación de fractura. Callo óseo. Trasplante óseo. Osteogénesis. Substancias de crecimiento. Proteínas morfogenéticas de hueso. Perros.

\section{Referências}

1. BENNET, D. Complications of fracture healing. In: COUGHLAN, A.; MILlER, A. (ed). Manual of small animal fracture repair and management. London: British Small Animal Veterinary Association, 1998. p. 329-335.

2. FROST, H. The biology of fracture healing: an overview for clinicians. Clinical Orthopaedics, v. 248, p. 283-293, 1989.

3. ROBEllo, G. T.; ARON, D. N. Delayed and nonunion fractures. Seminars in Veterinary Medicine and Surgery: Small Animal, v. 7, p. 98-104, 1992.

4. KADERLY, R.E. Delayed union, nonunion and malunion. In: SLATTER, D. (ed). Textbook of small animal surgery. 2. ed. Philadelphia: Saunders, 1993. p. 1676-1684.

5. BIRNBAUM, K. et al. Use of extracorporeal shock-wave therapy (ESWT) in the treatment of nonunions: a review of the literature. Archives of Orthopaedics and Trauma Surgery, v. 122, p. 324-330, 2002.

6. FINKEMEIER, C. G. Bone graft and bone graft substitutes. Journal of Bone and Joint Surgery, v. 84 A, p. 454-464, 2002.
7. PULEO, D. A. Biotheurapeutics in orthopaedics medicine: accelerating the healing process. Biodrugs, v. 17, p. 301-314, 2003.

8. ROSEN, H. apud ${ }^{3}$.

9. WEBER, B.; CECH, O. apud 3 .

10. SOUTHWOOD, L. L. et al. Evaluation of serum biochemical markers of bone metabolism for early diagnosis of nonunion and infected nonunion fractures in rabbits. American Journal of Veterinary Research, v. 64, p. 727-735, 2003.

11. MARKEL, M. D. et al. Atrophic nonunion can be predicted with dual energy $\mathrm{x}$-ray absorptiometry in a canine ostectomy model. Journal of Orthopaedical Research, v. 13, p. 869-875, 1995.

12. BOER, F. C. et al. Healing of segmental bone defect with granular porous hydroxyapatite augmented with recombinant human osteogenic protein-1 or autologous bone marrow. Journal of Orthopaedic Research, v. 21, p. 521-528, 2003.

13. QUARTO, R. et al. Repair of large bone defects with the use of autologous bone marrow stromal cells. New England Journal of Medicine, v. 344, p. 385-386, 2001. 
14. BRUDER, S. P. et al. The effect of implants loaded with autologous mesenchymal stem cells on the healing of canine segmental bone defects. Journal of Bone and Joint Surgery, v. 80A, p. 985-996, 1998.

15. KON, E. et al. Autologous bone marrow stromal cells loaded onto porous hydroxyapatite ceramic accelerate bone repair in critical-size defects of sheep long bones. Journal of Biomedical Material Research, v. 49, p. 328-337, 2000.

16. LIEBERMAN, J. R. et al. The role of growth factors in the repair of bone-biology and clinical applications. Journal of Bone and Joint Surgery, v. $84 \mathrm{~A}$, p. 1032-1044, 2002.

17. COOK, S. D. Preclinical and clinical evaluation of osteogenic protein-1 (BMP-7) in bony sites. Orthopedics, v. 22, p. 669-671, 1999.

18. ITOH, T. et al. Femoral nonunion fracture treated with recombinant human bone morphogenetic protein-2 in a dog. Journal of Veterinary Medical Science, v. 60, p. 535-538, 1998.

19. SCIADINI, M. F., JOHNSON, K. D. Evaluation of recombinant human bone morphogenetic protein-2 as a bone-graft substitute in a canine segmental defect model. Journal of Orthopaedical Research, v. 18, p. 289-302, 2000.

20. FRIEDLAENDER, G. E. et al. Osteogenic protein1 (bone morphogenetic protein-7) in the treatment of tibial nonunions. Journal of Bone Joint Surgery, v. 83A, p. 151-158. 2001. Supplement 1.

21. BLAESER, L. L. et al. Treatment of biologically inactive nonunions by a limited en bloc ostectomy and compression plate fixation: a review of 17 cases. Veterinary Surgery, v. 32, p. 91-100, 2003.
22. VACANTI, C. A.; BONASSAR, L J. An overview of tissue engineered bone. Clinical Orthopaedics and Related Research, n. 367, p. S375-S381, 1999. Supplement.

23. YANG, K. H.; PARK, S. J. Stimulation of fracture healing in a canine ulna full-defect model by lowintensity pulsed ultrasound. Yonsei Medical Journal, v 42, p. 503-508, 2001.

24. IKEDA, K. et al. Application of extracorporeal shock wave on bone: preliminary report. Journal of Trauma, v. 47, p. 946-950, 1999.

25. OWEN, M. A. Use of the Ilizarov method to manage a septic tibial fracture nonunion with a large cortical defect. Journal of Small Animal Practice, v. 41, p. 124-127, 2000.

26. RAHAL, S. C. et al. Acute shortening and subsequent lengthening of the radius and ulna for the treatment of an infected nonunion in a dog. Canine Veterinary Journal, v. 42, p.724-726, 2001.

27. HULSE, D. A. et al. Decision making in fracture mamangement. In: FOSSUM, T. W. (ed). Small animal surgery. Saint Louis: Mosby, 1997. p. $730-732$.

28. WELCH, J. A. et al. The intraosseous blood supply of the canine radius: implications for healing of distal fractures in small dogs. Veterinary Surgery, v. 26 , p. 57-61, 1997.

29. POLLOCK, C. et al. Postoperative management of the exotic animal patient. Veterinary Clinics of North America: Exotic Animal Practice, v. 5, p. 183-212, 2002. 